\title{
Foxl1-Cre-marked adult hepatic progenitors have clonogenic and bilineage differentiation potential
}

\author{
Soona Shin, ${ }^{1,2}$ Gabriel Walton, ${ }^{1,2}$ Reina Aoki, ${ }^{1,2}$ Karrie Brondell, ${ }^{1,2}$ Jonathan Schug, ${ }^{1,2}$ Alan Fox, ${ }^{1,2}$ \\ Olga Smirnova, ${ }^{1,2}$ Craig Dorrell, ${ }^{3}$ Laura Erker, ${ }^{3}$ Andrew S. Chu, ${ }^{4}$ Rebecca G. Wells, ${ }^{5}$ Markus Grompe, ${ }^{3}$ \\ Linda E. Greenbaum, ${ }^{6,7}$ and Klaus H. Kaestner ${ }^{1,2,8}$ \\ ${ }^{1}$ Department of Genetics, University of Pennsylvania School of Medicine, Philadelphia, Pennsylvania 19104, USA; ${ }^{2}$ Institute for \\ Diabetes, Obesity, and Metabolism, University of Pennsylvania School of Medicine, Philadelphia, Pennsylvania 19104, USA; \\ ${ }^{3}$ Oregon Stem Cell Center, Oregon Health and Science University, Portland, Oregon 97239, USA; ${ }^{4}$ Division of Gastroenterology, \\ Hepatology, and Nutrition, The Children's Hospital of Philadelphia, Pennsylvania 19104, USA; ${ }^{5}$ Department of Medicine, \\ University of Pennsylvania School of Medicine, Philadelphia, Pennsylvania 19104, USA; ${ }^{6}$ Departments of Cancer Biology, \\ Thomas Jefferson Medical College, Philadelphia, Pennsylvania 19107, USA; ${ }^{7}$ Medicine, Thomas Jefferson Medical College, \\ Philadelphia, Pennsylvania 19107, USA
}

Isolation of hepatic progenitor cells is a promising approach for cell replacement therapy of chronic liver disease. The winged helix transcription factor Foxl1 is a marker for progenitor cells and their descendants in the mouse liver in vivo. Here, we purify progenitor cells from Foxl1-Cre; RosaYFP mice and evaluate their proliferative and differentiation potential in vitro. Treatment of Foxl1-Cre; RosaYFP mice with a 3,5-diethoxycarbonyl-1, 4-dihydrocollidine diet led to an increase of the percentage of YFP-labeled Foxl1 ${ }^{+}$cells. Clonogenic assays demonstrated that up to $3.6 \%$ of Foxl1 ${ }^{+}$cells had proliferative potential. Foxl1 ${ }^{+}$cells differentiated into cholangiocytes and hepatocytes in vitro, depending on the culture condition employed. Microarray analyses indicated that Foxl1 ${ }^{+}$cells express stem cell markers such as Prom1 as well as differentiation markers such as Ck19 and Hnf4a. Thus, the Foxl1-Cre; RosaYFP model allows for easy isolation of adult hepatic progenitor cells that can be expanded and differentiated in culture.

[Keywords: Foxl1; liver; progenitor cells; bilineage; Sox9]

Supplemental material is available for this article.

Received January 3, 2011; revised version accepted March 31, 2011.

Chronic liver disease is a major health problem throughout the world. In 2007, 29,165 deaths were attributed to chronic liver disease in the United States alone (Xu et al. 2009). Although the liver possesses a remarkable regenerative capability and is able to reconstitute its parenchyma following an acute injury, this proliferative potential is impaired following chronic damage (Bird et al. 2008). Organ transplantation is the primary treatment for end-stage liver diseases but is limited by the lack of donor organs. Therefore, cell replacement therapy using bipotential hepatic progenitor cells has been proposed as an alternative way to treat the large number of patients. Hepatic progenitor cells are highly proliferative cells that are capable of differentiating into cholangiocytes and hepatocytes. For cell replacement therapy, it is critical to isolate hepatic progenitor cells, expand them in culture,

${ }^{8}$ Corresponding author.

E-MAIL kaestner@mail.med.upenn.edu; FAX (215) 573-5892.

Article is online at http://www.genesdev.org/cgi/doi/10.1101/gad.2027811. and characterize their biology. However, these efforts have been hindered due to the lack of specific markers allowing for easy isolation of these cells.

We reported previously that, while Foxl1-expressing cells are undetectable in the healthy liver, Foxll expression is dramatically induced in the liver after bile duct ligation or in mice fed a 3,5-diethoxycarbonyl-1,4-dihydrocollidine (DDC)-containing diet. Foxll-Cre-expressing cells appeared within the periportal region where the ductular reaction occurs. Previously (Sackett et al. 2009b), we had employed Foxl1-Cre; Rosa26R lacZ mice for genetic lineage tracing of Foxll-expressing cells and their descendants in vivo. The number of CK19-expressing cells (cholangiocytes) and HNF4 $\alpha$-expressing cells (hepatocytes) that were colabeled with $\beta$-gal increased over time. However, it remained unclear whether a single Foxl1-Cre-positive cell can differentiate into two different lineages, or whether separate populations of Foxl1expressing cells contributed to each lineage. Therefore, we investigated whether Foxll-expressing cells have 
Shin et al.

clonogenic potential with bipotential differentiation capabilities in vitro using the new Foxll-Cre; RosaYFP model.

\section{Results}

Labeling of the Foxl1-Cre lineage in RosaYFP mice fed a DDC diet

We previously used the Rosa26R lacZ reporter for lineage tracing of Foxll-expressing cells in vivo. However, this model cannot be adapted easily for isolating viable cells using flow cytometry. Therefore, we crossed the Foxl1Cre line (Sackett et al. 2007) to Rosa26-YFP reporter mice (Srinivas et al. 2001) in which the yellow fluorescent protein (YFP) is expressed only after Cre-mediated excision of a loxP-flanked stop codon. In order to induce liver injury and Foxll expression, Foxl1-Cre; RosaYFP mice were fed a DDC-supplemented diet. DDC inhibits protoheme ferro-lyase activity, resulting in accumulation of protoporphyrin in hepatocytes, eventually leading to a ductular reaction and cholangitis (Tephly et al. 1979; Fickert et al. 2007). Treatment with DDC has been reported to induce proliferation of bipotent progenitor cells (Kamiya et al. 2009). When Foxl1-Cre; RosaYFP mice were fed a DDC diet for $14 \mathrm{~d}$, multiple cells in the portal triad were labeled by the Foxl1-Cre transgene in this model (Fig. 1).

\section{Isolation of Foxl1-Cre-expressing cells} from nonparenchymal cells

To determine the number of $\mathrm{YFP}^{+}$cells that were induced in response to the DDC diet, we performed fluorescenceactivated flow cytometry cell sorting (FACS) analysis using nonparenchymal cells that were stained with an antibody against hematopoietic marker CD45 for countersorting of hematopoietic cells. The $\mathrm{YFP}^{+}$cell number increased after treatment with the DDC diet, while there were no detectable $\mathrm{YFP}^{+}$cells in the liver of mice fed a chow diet, consistent with prior studies on Foxl1 expression in vivo (Fig. 2A,B; Sackett et al. 2009b). To determine whether Foxl1-Cre efficiently labeled Foxl1expressing cells, we sorted $\mathrm{YFP}^{+}$and $\mathrm{YFP}^{-}$cells and measured mRNA levels of Foxl1 using quantitative PCR. As shown in Figure $3 \mathrm{~A}, \mathrm{YFP}^{+}$cells were dramatically enriched for Foxl1 mRNA compared with $\mathrm{YFP}^{-}$ cells and total liver.

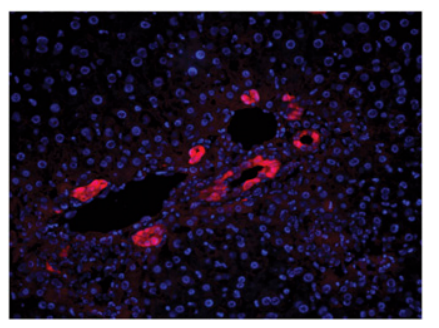

Figure 1. Labeling of the Foxl1-Cre lineage in RosaYFP mice. $\mathrm{YFP}^{+}$cells are present within the periportal region in an injured mouse liver.

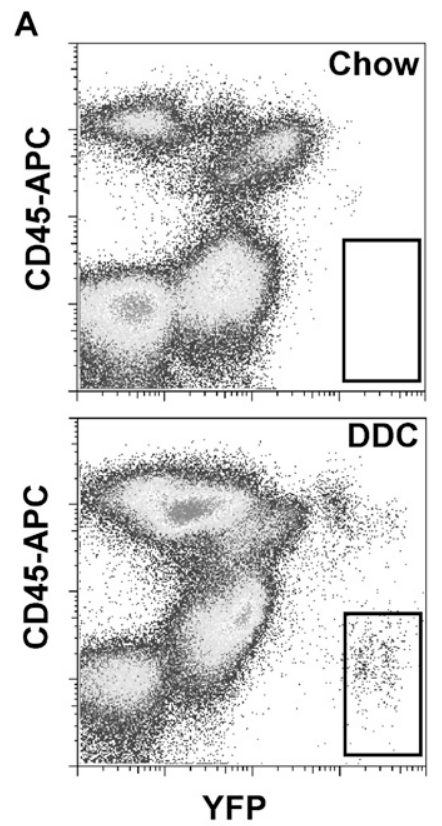

B

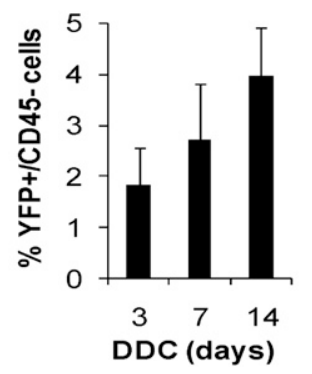

Figure 2. $\mathrm{YFP}^{+}$cell number increases after treatment with a DDC-supplemented diet. (A) FACS data of nonparenchymal cells from the liver of Foxl1-Cre; RosaYFP mice fed chow or DDC diets. CD45 is a marker for hematopoietic cells. (Rectangle) $\mathrm{CD} 45^{-} / \mathrm{YFP}^{+}$fraction. (B) A time-dependent increase of $\mathrm{CD} 45^{-} / \mathrm{YFP}^{+}$cells is shown. Data are represented as mean \pm SEM.

\section{Fox $11^{+}$cells are capable of self-renewal}

Stem cells and/or progenitor cells are characterized by their ability to self-renew and generate differentiated cells. To evaluate our hypothesis that Foxl1-Cre-expressing cells are hepatic progenitor cells, we performed in vitro clonogenic assays with sorted $\mathrm{YFP}^{+}$cells and $\mathrm{YFP}^{-}$ cells. As shown in Figure $3 \mathrm{C}, \mathrm{YFP}^{+}$cells were able to generate colonies derived from a single cell. These cells retained their proliferative capability after 15 passages. The clonogenic potential of $\mathrm{YFP}^{+}$cells was dramatically higher than that of $\mathrm{YFP}^{-}$nonparenchymal cells (Fig. 3B), and reached up to $3.6 \%$ of the plated cells in some experiments.

\section{Foxl1 ${ }^{+}$cells possess bilineage potential}

We reported previously that Foxl1-Cre-marked cells differentiate into both cholangiocytes and hepatocytes in vivo (Sackett et al. 2009b). However, these in vivo 
A

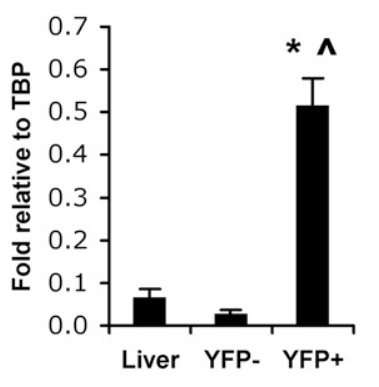

B

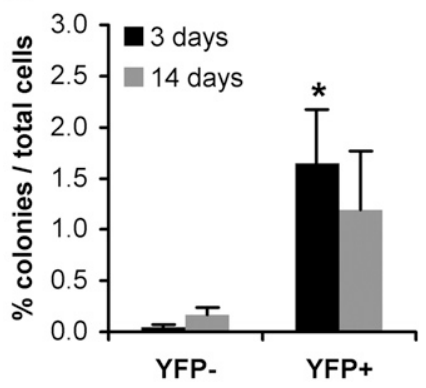

C

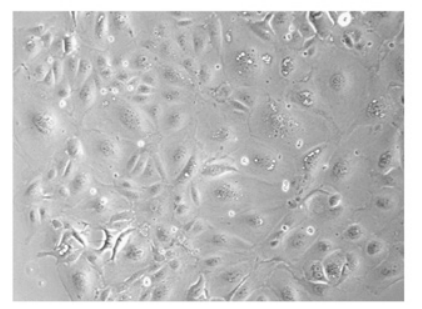

Figure 3. Foxl $1^{+}$cells are capable of self-renewal. $(A) \mathrm{YFP}^{+}$cells are enriched for Foxl1. mRNA levels of Foxl1 are shown; $\left(^{\star}\right) P<$ 0.05 , liver versis $\mathrm{YFP}^{+} ;\left(^{\wedge}\right) P<0.05$, $\mathrm{YFP}^{-}$versus $\mathrm{YFP}^{+}(n=4) .(B)$ Percent of colonies over total number of cells. $\left(^{\star}\right) P<0.05(n=6)$. Data are represented as mean \pm SEM. $(C) \mathrm{YFP}^{+}$and $\mathrm{YFP}^{-}$cells from Foxl1-Cre; RosaYFP mice were cultured for $7 \mathrm{~d}$. A representative colony is shown.

experiments could not establish whether a single Foxl1$\mathrm{Cre}^{+}$cell could give rise to both lineages. To determine whether a single Foxll-Cre ${ }^{+}$cell is bipotential, we used clonal cell lines derived from individual cells for in vitro differentiation experiments. Morphogenesis is a key step of bile duct development (Tanimizu et al. 2007). A number of reports have used culturing in type I collagen gels to induce cholangiocytic characteristics (i.e., formation of tube-like branched structures) as the assay for cholangiocyte differentiation (Tanimizu et al. 2007; Kamiya et al. 2009). When clones obtained from sorted $\mathrm{YFP}^{+}$cells were cultured in type I collagen gels supplemented with tumor necrosis factor $\alpha(\mathrm{TNF} \alpha)$, cells developed extensive branching morphology changes (Fig. 4A,F). These duct-like cells were positive for CK19, as expected for cholangiocytes (Fig. 4B). These data indicate that Foxll-Cre ${ }^{+}$cells can be differentiated along the cholangiocyte lineage in vitro.

To prove that Foxl1-Cre ${ }^{+}$cells are bipotential, we used eight clones that were able to exhibit cholangiocytic differentiation in collagen gel for hepatocyte differentiation experiments. When induced by culture in a medium supplemented with Matrigel and oncostatin M, cells from seven cell lines activated expression of glucose-6-phosphatase $(G 6 p c)$ and tyrosine aminotransferase (Tat), enzymes expressed only in mature hepatocytes (Fig. 4E,F). To test whether cells differentiated into hepatocytes possess functional properties of mature hepatocytes, we performed Periodic acid-Schiff staining to detect glycogen deposition. Glycogen deposition was detected in cells differentiated into hepatocytes (Fig. 4D) but not in untreated cells (Fig. 4C).

Next, we compared the gene expression profile of Foxl1-Cre ${ }^{+}$cells differentiated in vitro with the gene expression profile of primary hepatocytes and cholangiocytes. As shown in Supplemental Figure S1, in vitro differentiated hepatocytes clustered with primary hepatocytes, indicative of successful in vitro differentiation. Primary cholangiocytes and in vitro differentiated cholangiocytes clustered separately from hepatocytes, as expected, but in vitro differentiated cholangiocytes were closer to undifferentiated cells than primary cholangiocytes on the heat map. When we analyzed the expression profile using an MvA plot $(\mathrm{M}=$ ratio; $\mathrm{A}=$ average
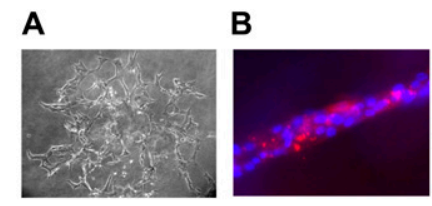

C

D
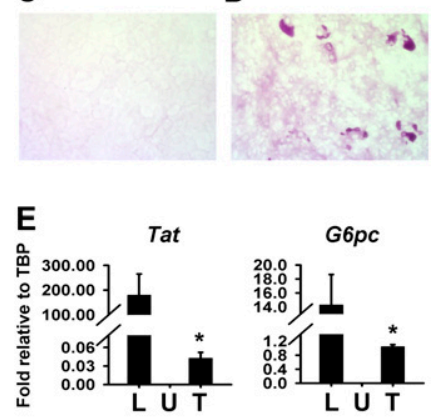

$\mathbf{F}$

\begin{tabular}{l|l} 
Induction & Clones \\
\hline Cholangiocytes & $8 / 8$ \\
Hepatocytes & $7 / 8$
\end{tabular}

Figure 4. Foxl $1^{+}$cells are capable of differentiating into cholangiocytes and hepatocytes. (A) Foxl1 $1^{+}$cells differentiate into duct-like cells when stimulated by collagen type 1A and TNF $\alpha$. (B) Immunofluorescence staining of duct-like cells for CK19 (red) and nuclei (blue). $(C, D)$ Periodic acid-Schiff staining of untreated cells $(C)$ and cells differentiated into hepatocytes for $21 \mathrm{~d}(D) .(E)$ mRNA levels of hepatocyte markers. Foxl1 ${ }^{+}$cells were treated with Matrigel and oncostatin $M$ for $7 \mathrm{~d}(n=4)$. (L) Liver; $(\mathrm{U})$ undifferentiated; $(\mathrm{T})$ differentiated. Data are represented as mean \pm SEM. $\left({ }^{\star}\right) P<0.05$, untreated versus treated. $(F)$ Number of clonal cell lines that have bilineage potential. 
intensity), in vitro differentiated cholangiocytes expressed Krt19, Krt7, Onecut2, and isoforms of $\gamma$ glutamyltasferases (Ggt1, Ggt6, and Ggt7), the levels of which were comparable with primary cholangiocytes (Supplemental Fig. S2). These results imply that the gene expression profile of in vitro differentiated cholangiocytes shifted toward that of primary cholangiocytes, but in vitro differentiation of cholangiocytes was incomplete. Taken together, our results indicate that Foxl1-Cre ${ }^{+}$cells are able to differentiate into both hepatic epithelial lineages.

\section{Foxl1-Cre ${ }^{+}$cells express markers of hepatic progenitors}

Numerous markers of hepatic progenitor cells have been identified, but none of these markers are completely specific for the progenitor compartment (Bird et al. 2008). To determine whether Foxl1-Cre ${ }^{+}$cells express these markers, Foxl1-Cre; RosaYFP mice were fed a DDC diet for 3, 7, and $14 \mathrm{~d}$, and $\mathrm{YFP}^{+}$and $\mathrm{YFP}^{-}$were isolated from total nonparenchymal cells that are negative for CD45. Total nonparenchymal cells from chow-fed mice were used as controls. Previous work from our laboratory indicated that Foxll marks not only hepatic progenitors, but also their descendants (Sackett et al. 2009b). Therefore, the YFP-labeled cells represent a mixture of progenitor cells and differentiated cells. Our prediction was that mRNA levels of progenitor markers would decrease over time with a corresponding increase in mRNA levels of differentiation markers. To determine whether Foxl1$\mathrm{Cre}^{+}$cells express progenitor cell markers and whether these markers decrease with prolonged differentiation, Foxl1-Cre; RosaYFP mice were fed a DDC diet for 3, 7, and $14 \mathrm{~d}$, and $\mathrm{YFP}^{+}$and $\mathrm{YFP}^{-}$were isolated from total nonparenchymal cells that are negative for CD45. Total nonparenchymal cells from chow-fed mice were used as controls.

However, as shown in Figure 5, mRNA levels of progenitor markers Epcam (Tacstd1), Prom1, Cd44, and Trop2 (Tacstd2) were highly enriched in $\mathrm{YFP}^{+}$cells from day 3 and/or day 7 and continued to be expressed on day 14 , suggesting that the injured liver continues to generate more progenitor cells as long as the mice are fed DDC (Bird et al. 2008; Kamiya et al. 2009; Okabe et al. 2009; Rountree et al. 2009). Other markers of the progenitor compartment-such as Cldn3, Ncam1, Dlk1, and Onecut2-are enriched in the $\mathrm{YFP}^{+}$population only at day 14 , indicating that previously reported markers can be classified to early markers and later markers (Schmelzer et al. 2006; 2007; Snykers et al. 2009; Tanaka et al. 2009). In addition, $\mathrm{YFP}^{+}$cells were enriched for cholangiocyte markers Ck19 (Krt19), Ck7 (Krt7), Onecut1, and Hnf1b, as well as hepatocyte markers $H n f 4 a, H n f 1 a$, and Prox1 (Dudas et al. 2006; data not shown). YFP $^{+}$cells were not enriched for terminal hepatocyte markers such as $G 6 p c$ and Tat because we excluded mature hepatocytes during the cell isolation protocol (Materials and Methods). We previously used the Foxl1-Cre; Rosa26R lacZ mouse to trace expression of Foxl1-Cre in vivo and report the appearance of $\beta$-gal ${ }^{+} \mathrm{CK} 19^{+}$cells and $\beta$-gal ${ }^{+} \mathrm{HNF} 4 \alpha^{+}$cells,

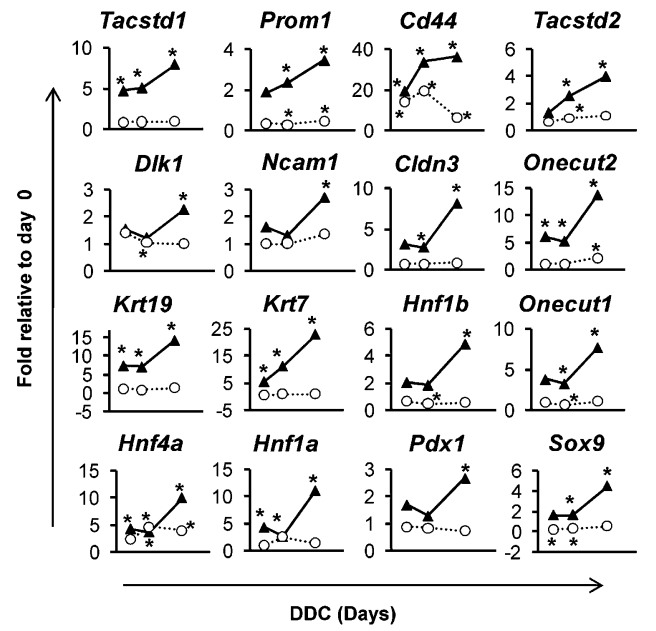

Figure 5. Microarray analyses of Foxl1 $^{+}$and Foxl1 ${ }^{-}$cells. Foxl1-Cre; RosaYFP mice were fed a chow diet (day 0) or a DDC diet for 3,7 , and $14 \mathrm{~d}(n=4)$. Expression levels are shown relative to day 0 nonparenchymal cells. (Closed triangle, solid line) $\mathrm{YFP}^{+}$; (open circle, dotted line) $\mathrm{YFP}^{-} ;\left(^{*}\right)$ false discovery rate $(\mathrm{FDR})<20$, versus day 0 .

but not $\beta$-gal ${ }^{+} \mathrm{CK} 19^{+} \mathrm{HNF} 4 \alpha^{+}$cells (Sackett et al. 2009b). Therefore, we believe that $\mathrm{YFP}^{+}$cells are a mixture of different populations, including undifferentiated progenitor cells and descendants of $\mathrm{YFP}^{+}$cells that have partially or fully differentiated into hepatocytes and cholangiocytes. These data support our hypothesis that Foxl1-Cre marks progenitor cells that can differentiate into cholangiocytes and hepatocytes. Interestingly, $\mathrm{YFP}^{+}$cells are also enriched for $P d x 1$, a marker of pancreatic progenitor cells (Seymour et al. 2007).

In order to compare the gene expression profiles of $\mathrm{YFP}^{+}$ cells from different time points, we performed functional analysis of genes that showed differential expression between day 0 nonparenchymal cells and $\mathrm{YFP}^{+}$cells at DDC days 3 and 14 (Supplemental Fig. S3A). $\mathrm{YFP}^{+}$cells from day 3 were enriched for the genes involved in cellular growth and proliferation, function, and maintenance. On the other hand, $\mathrm{YFP}^{+}$cells from day 14 were enriched for the genes involved in lipid metabolism, molecular transport, and small molecule biochemistry. These data confirm that the $\mathrm{YFP}^{+}$fraction from day 14 is more enriched for differentiated cells compared with day 3. In addition, $\mathrm{YFP}^{+}$cells from DDC 3 and $14 \mathrm{~d}$ are enriched for genes involved in cellular movement and cell-to-cell interaction, implying a putative involvement of cell migration in progenitor function.

Microarray analyses demonstrated that 8817 genes are differentially expressed in $\mathrm{YFP}^{+}$and $\mathrm{YFP}^{-}$cells compared with day 0 nonparenchymal cells (Supplemental Fig. $\mathrm{S} 3 \mathrm{C}$ ). We grouped these 8817 genes into 10 clusters based on centroid-based cluster analysis (Supplemental Fig. S3B). Two-thousand-fifty genes that were grouped into cluster 3 were enriched in $\mathrm{YFP}^{+}$cells but not $\mathrm{YFP}^{-}$cells. Functional analysis indicated that these genes were involved in development, but also in cell junction, cell 
adhesion, and cytoskeleton (Supplemental Fig. S3D). These data imply that cell-to-cell interaction might play an important role in progenitor cell function.

\section{Fox $11^{+}$progenitors are a subset of Sox $9^{+}$progenitors}

In an accompanying study in this issue of Genes \& Development, Dorrell et al. (2011) employ a set of cell surface markers to sort a related population of adult progenitor cells from the livers of DDC-treated mice. These cells were further shown to be enriched for expression of the transcription factor Sox9, expression of which we also found to be activated in our Foxl1-Cre, $\mathrm{YFP}^{+}$cells (Fig. 5). In addition, Furuyama et al. (2011) have demonstrated very recently that a subset of cells that are self-renewable and have the capacity to supply hepatocytes are located within Sox9-expressing cells in the mouse liver. In order to clarify the relationship between Sox $9^{+}$and Foxl1 $1^{+}$progenitors, we performed dual-label immunofluorescent staining of livers from DDC-treated mice. As shown in Figure 6, Foxl1-Cre, $\mathrm{YFP}^{+}$cells
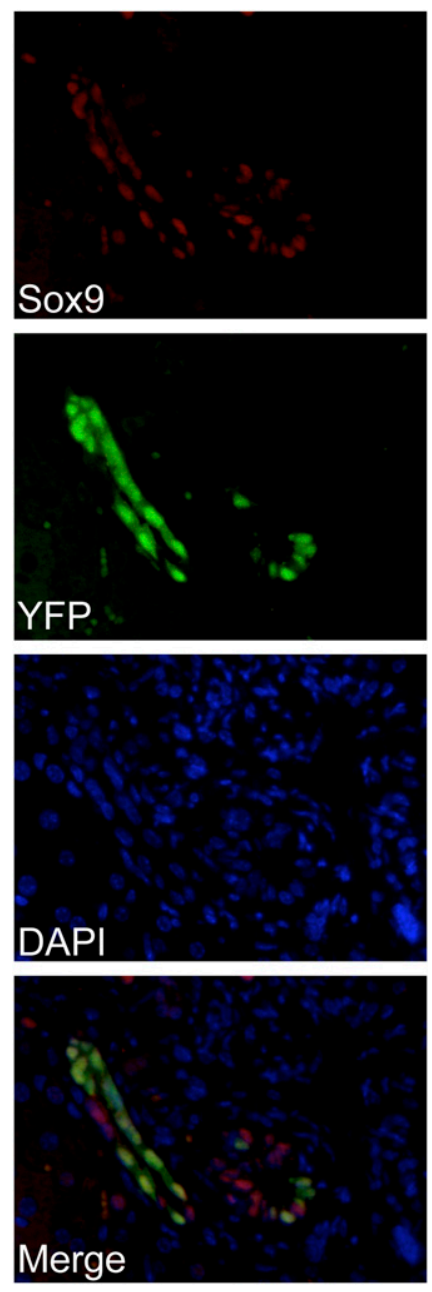

Figure 6. Foxl1-Cre; $\mathrm{YFP}^{+}$cells are a subset of Sox $9^{+}$cells. Representative images from the liver of a Foxll-Cre; RosaYFP mouse fed a DDC diet for $7 \mathrm{~d}$ are shown. represent a subset of the Sox $9^{+}$population, such that all $\mathrm{YFP}^{+}$cells are also Sox $9^{+}$, but many Sox $9^{+}$cells are $\mathrm{YFP}^{-}$. Of the Sox $9^{+}$cells in the ductal area, $51 \% \pm 7 \%$ were positive for YFP. The immunofluoresence staining also indicates that there are varying levels of Sox 9 protein in different liver cells. Thus, the increase in Sox 9 expression we see from day 3 to day 14 of DDC treatment (Fig. 5) is likely the result of higher Sox9 expression within the Foxl1-Cre-marked lineage.

\section{Discussion}

The mammalian genome encodes $>40$ forkhead box transcription factors. These proteins have been shown to regulate important biological functions such as control of the cell cycle, differentiation of epithelia, placental development, and formation of the inner ear (Hannenhalli and Kaestner 2009). In the liver, the Foxa, Foxl1, Foxm1, and Foxo genes have been shown to control both formation and function of the liver (Le Lay and Kaestner 2010). Foxll was originally identified as a mesenchymal marker in the stomach and intestine, and its expression is not detected in healthy adult and fetal livers (Kaestner et al. 1996; Sackett et al. 2009b). Previously, we demonstrated that Foxl1 marks highly proliferating cells that give rise to $\mathrm{CK} 19^{+}$cells and $\mathrm{HNF} 4 \alpha^{+}$cells in an injured liver in vivo (Sackett et al. 2009b). Here we show that Foxl1$\mathrm{Cre} \mathrm{YFP}^{+}$cells are self-renewable and bipotential in vitro.

Foxl1-Cre; $\mathrm{YFP}^{+}$cells were highly enriched for Foxl1 mRNA, and high expression levels of Foxl1 were retained in the clonal cell lines established from $\mathrm{YFP}^{+}$cells. The fact that Fox 11 mRNA levels were lower in cells differentiated into hepatocytes than in undifferentiated cells implies that Foxll might play a role in maintaining the stemness of progenitor cells (Supplemental Fig. S4). However, cells transfected with shRNAs against Foxl1 expressed lower levels of G6pc mRNA when stimulated for differentiation compared with control cells, suggesting that Foxl1 might be also required for differentiation. We reported previously that livers of Foxl1-null mice exhibit an increase in necrosis following bile duct ligation (Sackett et al. 2009a). Additional experiments using Foxl1-null mice will be required to determine the role of Foxll in the function of the progenitor compartment. According to the microarray analyses, mRNAs for other forkhead box genes such as Foxa1, Foxa2, Foxb2, Foxe1, Foxe3, Foxj1, Foxn4, and Foxp4 were enriched in $\mathrm{YFP}^{+}$ cells but not $\mathrm{YFP}^{-}$cells, implying that the forkhead box gene family might play important roles during liver repair.

Microarray analysis indicated that Foxl1-Cre; $\mathrm{YFP}^{+}$ cells were enriched for progenitor markers but not for Sox2, Nanog, and Klf4 (data not shown), suggesting that these cells are tissue-committed progenitor cells. It has been proposed that stem cells that reside in the liver generate progenitor cells (Bird et al. 2008). Other groups have proposed that progenitor cells originate from the bone marrow (Matthews and Yeoh 2005). The fact that the earliest Foxl1-Cre; $\mathrm{YFP}^{+}$expression in the injured liver occurs in $\mathrm{CK}_{1} 9^{+}$cholangiocytes (Sackett et al. 
Shin et al.

2009 b), and that primary cholangiocytes express progenitor markers (Supplemental Fig. S2), suggests but does not prove that the Foxl1-marked progenitor is a liver-resident cell. Interestingly, Foxl1-Cre; $\mathrm{YFP}^{+}$cells express $P d x 1$ and Sox9, which is consistent with the common embryonic origin of the pancreas and liver from endoderm. In summary, our findings demonstrated that Foxl1-Cre is a useful marker to isolate and characterize hepatic progenitor cells, suggesting a broader application of this lineage-tracing approach.

\section{Materials and methods}

\section{Materials}

Nicotinamide and dexamethasone were purchased from Sigma. Hepatocyte growth factor, epidermal growth factor, and TNF $\alpha$ were from Peprotech. Matrigel, allophycocyanin-conjugated anti-CD45, and collagen-I-coated plates were from BD Biosciences. All other materials and reagents were from Invitrogen unless specified.

\section{Mice}

For lineage-tracing studies, Foxl1-Cre mice (Sackett et al. 2007) were crossed to Rosa26R YFP reporter mice (Srinivas et al. 2001) and fed a diet containing 0.1\% DDC (Harlan Teklad, TD.07762) for 3, 7, or 14 d. Foxl1-Cre-negative mice fed a DDC diet or Foxl1Cre mice fed a chow diet were used as controls. Animals (6-10 wk old) were anesthetized with $2.5 \% \mathrm{vol} / \mathrm{vol}$ vaporized isoflurane. All protocols were approved by the Institutional Animal Care and Use Committee of the University of Pennsylvania.

\section{Immunofluorescence staining}

At times of sacrifice, livers were rinsed in phosphate-buffered saline (PBS) and placed in $4 \%$ paraformaldehyde for $45 \mathrm{~min}$, rinsed in PBS, and cryoprotected in 10\%, 20\%, and 30\% sucrose/ PBS overnight at $4{ }^{\circ} \mathrm{C}$. Frozen sections were warmed to room temperature for $3 \mathrm{~min}$, rinsed in PBS, and blocked with PBS/ $0.25 \%$ Trion $\mathrm{X}-100 / 3 \%$ donkey serum for $1 \mathrm{~h}$ at room temperature. For staining of YFP, sections were incubated with an antiGFP rabbit antibody (Abcam) overnight at $4^{\circ} \mathrm{C}$. Sections were rinsed in PBS and incubated with Cy3-conjugated donkey antirabbit immunoglobulin G (Jackson ImmunoResearch Laboratories). Sections were washed twice in PBS for $5 \mathrm{~min}$, in 4', 6-diamidino-2-phenylindole (Invitrogen) for $5 \mathrm{~min}$, and in $\mathrm{ddH}_{2} \mathrm{O}$ twice for $5 \mathrm{~min}$, and were mounted with fluorescent mounting media. For costaining of Sox 9 and YFP, livers were rinsed in PBS and placed in $4 \%$ paraformaldehyde overnight, rinsed in PBS, and embedded in paraffin. An antigen retriever $(2100$ Retriever, PickCell Laboratories) was used to pretreat deparaffinized sections on slides. Sections were stained with an anti-GFP goat antibody (Abcam) and an anti-Sox9 rabbit antibody (Millipore).

\section{Isolation of YFP $P^{+}$cells using a FACS sorter}

Isolation of nonparenchymal cells from livers was performed according to the two-step collagenase digestion (Kamiya et al. 2009). Briefly, the liver of a Foxl1-Cre; RosaYFP mouse was perfused with liver perfusion medium and liver digestion medium (Invitrogen). The digested liver was further dissociated by incubating in $0.25 \%$ collagenase solution for $30 \mathrm{~min}$ at $37^{\circ} \mathrm{C}$. The large hepatocyte fraction was removed from nonparenchymal cells by low-speed sedimentation ( $50 \mathrm{~g}$ for $2 \mathrm{~min}$ ). Non- parenchymal cells were collected $(300 \mathrm{~g}$ for $5 \mathrm{~min})$ and resuspended in serum-free medium (Kubota and Reid 2000). Cells were incubated with APC-conjugated anti-CD45 for $20 \mathrm{~min}$ and washed several times in PBS with $2 \%$ fetal bovine serum. FACSCalibur and FACSDiva (BD Biosciences) were used for analysis and sorting. Forward scatter and side scatter were used to exclude debris and cell doublets. Dead cells were stained using 7-aminoactinomycin D or 4',6-diamidino-2-phenylindole. $\mathrm{YFP}^{+}$ and $\mathrm{YFP}^{-}$fractions were sorted from viable nonparenchymal cells that were negative for CD45.

\section{Clonogenic assay and establishment of clones}

Conditioned medium was derived from embryonic day 14.5 (E14.5) liver cells (Kamiya et al. 2009) and mixed with the same volume of hepatic colony-forming medium (Dulbecco's modified Eagle medium/F-12, 10\% fetal bovine serum, insulin-transferrin-selenium-X, $10 \mathrm{mmol} / \mathrm{L}$ nicotinamide, $10^{-7} \mathrm{~mol} / \mathrm{L}$ dexamethasone, $2.5 \mathrm{mmol} / \mathrm{L}$ HEPES, penicillin/streptomycin/l-glutamine). Hepatocyte growth factor $(40 \mathrm{ng} / \mathrm{mL})$, epidermal growth factor $(20 \mathrm{ng} / \mathrm{mL})$, and Y-27632 (20 $\mu \mathrm{M})$ (EMD4Biosciences) were also added. $\mathrm{YFP}^{+}$and $\mathrm{YFP}^{-}$cells were sorted as single-cell suspension, resuspended in the medium described above, plated at a low density (1000 cells per collagen-I-coated $35-\mathrm{mm}$ dish) to avoid clustering of cells, and cultured for $7 \mathrm{~d}$. Each colony was defined as a cluster with at least 20 cells. Each colony was picked and transferred into a collagen-I-coated 96-well plate. The expanded cells were transferred into collagen-I-coated 24-well plates and six-well plates. Eight clones (each derived from a single cell) were used for in vitro differentiation experiments.

\section{Induction of cholangiocyte and hepatocyte differentiation}

For induction of cholangiocyte differentiation, 10,000 cells were suspended in $0.5 \mathrm{~mL}$ of DMEM/F12 mixed with $0.5 \mathrm{~mL}$ of type I collagen gel solution (Nitta Gelatin). This mixture was added onto a 24-well plate. After $30 \mathrm{~min}$ of incubation at $37^{\circ} \mathrm{C}, 1 \mathrm{~mL}$ of medium (Dulbecco's modified Eagle medium supplemented with $10 \%$ fetal bovine serum, insulin-transferrin-selenium $\mathrm{X}$, $20 \mathrm{ng} / \mathrm{mL}$ hepatocyte growth factor, $50 \mathrm{ng} / \mathrm{mL}$ TNF $\alpha$ ) was added on top. The culture continued for $21 \mathrm{~d}$ (Kamiya et al. 2009). For induction of hepatocyte differentiation, cells were grown to confluence, washed with PBS twice, and cultured in medium supplemented with $20 \%$ Matrigel, $40 \mathrm{ng} / \mathrm{mL}$ oncostatin M (R\&D Systems), $20 \mathrm{ng} / \mathrm{mL}$ hepatocyte growth factor, $10 \mathrm{ng} / \mathrm{mL}$ fibroblast growth factor 4 (R\&D Systems), and $10^{-7} \mathrm{~mol} / \mathrm{L}$ dexamethasone for $7 \mathrm{~d}$ (Schwartz et al. 2002; Kamiya et al. 2009).

\section{Isolation of primary cholangiocytes and hepatocytes}

Primary cholangiocytes were isolated from the liver of a Alfp-Cre $\times$ RosaYFP mouse and a BALB/c mouse as described previously (Chu et al. 2011). For hepatocyte isolation, the liver of a Foxl1Cre; RosaYFP mouse was perfused with liver perfusion medium and liver digestion medium (Invitrogen). Digested cells were centrifuged at $80 \mathrm{~g}$ for $3 \mathrm{~min}$ in $25 \%$ Percoll (GE Healthcare). Dead cells were removed from hepatocytes by aspirating the supernatant.

\section{RNAi for knockdown of Foxl1}

$\mathrm{YFP}^{+}$cells cultured on a collagen-I-coated $35-\mathrm{mm}$ dish were transfected with green fluorescence protein (GFP)-labeled shRNA plasmids. Two micrograms of plasmid expressing nonsilencing shRNA control and two different shRNA constructs targeting Foxl1 (shRNA1 and shRNA2) (Open Biosystems) were 
mixed with $10 \mu \mathrm{L}$ of Arrest-In and added to each well. GFP fluorescence from transfected cells was higher than YFP fluorescence from untransfected cells. Therefore, transfected cells were sorted for GFP using FACS from undifferentiated cells or cells differentiated into hepatocytes for $3 \mathrm{~d}$ and snap-frozen for subsequent gene expression analysis.

\section{Periodic acid-Schiff's staining}

Glycogen was stained using Periodic acid-Schiff staining system (Sigma). Cells grown on chamber slides were fixed with $4 \%$ PFA for $30 \mathrm{~min}$ and washed with PBS twice. Next, slides were incubated in Periodic acid solution for $5 \mathrm{~min}$ and rinsed with several changes of distilled water. Slides were incubated in Schiff's reagent for $15 \mathrm{~min}$, washed in running tap water for 5 min, dehydrated, and mounted with xylene-based mounting medium.

\section{RNA isolation and quantitative real-time PCR}

Total RNA was extracted from liver samples and sorted cells using Trizol and RNeasy minikit (Qiagen) according to the manufacturer's instructions. Liver RNA was reverse-transcribed using oligo dT priming and SuperScript II reverse transcriptase. PCR reactions were performed using SYBR Green QPCR Master Mix (Agilent Technologies) on an Mx3000 PCR cycler (Agilent Technologies). Reactions were performed in triplicate with reference dye normalization, and median CT values were used in the analyses. Primer sequences for Foxl1, Tbp, Tat, and G6pc are as described previously (Kamiya et al. 2009; Sackett et al. 2009b).

\section{Microarray expression profiling}

Total RNA from each sample was used for labeling and hybridization. For comparison between primary $\mathrm{YFP}^{+}$and $\mathrm{YFP}^{-}$cells, cDNA was prepared using the WT-Ovation Pico Amplification System (NuGEN Technologies). Amplified cDNA was directly labeled using the BioPrime Array CGH Genomic Labeling System with Cy3-labeled nucleotides (GE Amersham Biosciences). RNAs from all of the other samples were amplified and labeled using Low-Input Quick Amp labeling kits (Agilent Technologies). Labeled samples were hybridized overnight to the Agilent 4X44 Whole Mouse Genome Array. Arrays were washed and then scanned with the model G2565B Agilent DNA microarray scanner (Agilent Technologies). Median intensities of each element on the array were captured with Agilent Feature Extraction version 9.53 (Agilent Technologies). Quality control diagnostic plots were prepared for each array, and those failing to exhibit high-quality hybridizations were excluded from further analysis, resulting in the final data set containing four biological replicates for each condition. The subsequent analysis was performed as shown previously (Rieck et al. 2009). Gene functional classification was performed on differentially expressed genes with $>1.5$-fold, using Ingenuity Pathways Analysis (Ingenuity Systems, http://www.ingenuity.com) and DAVID Bioinformatics resources (National Institutes of Health) (Dennis et al. 2003; Huang et al. 2009). The clustering analysis was performed using TIGR Multiexperiment Viewer software $\left(\mathrm{MeV}_{\text {; }}\right.$ The Institute for Genomic Research) (Saeed et al. 2003; Saeed et al. 2006). All expression data were deposited into Gene Expression Omnibus (accession no. GSE28892).

\section{Hierarchical clustering of samples and genes}

Using the microarray data, a gene list was assembled from the intersection of genes differentially expressed in one or more of these data sets: (1) untreated $\mathrm{YFP}^{+}$cells from four clonal cell lines, (2) $\mathrm{YFP}^{+}$cells from four clonal cell lines differentiated into hepatocytes, (3) $\mathrm{YFP}^{+}$cells from three clonal cell lines differentiated into cholangiocytes, (4) primary hepatocytes from four Foxl1-Cre; RosaYFP mice, and (5) primary cholangiocytes from one Alfp-Cre $\times$ RosaYFP mouse (Chu et al. 2011) and three $\mathrm{BALB} / \mathrm{c}$ mice (pooled). Three-hundred-ninety-nine genes that match the following criteria were used for analysis: (1) enriched in undifferentiated cells in at least two comparisons, (2) enriched in differentiated hepatocytes and primary hepatocytes compared with undifferentiated cells, (3) enriched in differentiated cholangiocytes and primary cholangiocytes compared with undifferentiated cells, and (4) fold change of $\geq 5$ and false discovery rate (FDR) $\leq 1$. TIGR MeV (Saeed et al. 2003; Saeed et al. 2006) was used to view the expression image or heat map and to cluster the samples and genes.

\section{Statistical analysis}

Student's $t$-tests with equal variance and two-tailed distribution were used to determine the significance of differences between two groups (Excel statistical analysis software). A $P$-value of 0.05 was considered statistically significant.

\section{Acknowledgments}

We thank the Flow Cytometry Laboratory (University of Pennsylvania) for help with FACS sorting, Ben Taterka for immunofluorescence staining, and the DERC Functional Genomics Core for expression analysis (P30-DK19525). We thank Dr. A. Kamiya (University of Tokyo) and Dr. L. Reid (University of North Carolina) for advice on the clonogenic assay and in vitro differentiation. This work was supported by grants to K.H.K. (P01 DK049210) from the National Institute of Health, to L.E.G. from the Fred and Suzanne Biesecker Center for Pediatric Disease, and to L.E.G. and K.H.K. from the University of Pennsylvania Institute for Regenerative Medicine.

\section{References}

Bird TG, Lorenzini S, Forbes SJ. 2008. Activation of stem cells in hepatic diseases. Cell Tissue Res 331: 283-300.

Chu AS, Diaz R, Hui JJ, Yanger K, Zong Y, Alpini G, Stanger BZ, Wells RG. 2011. Lineage tracing demonstrates no evidence of cholangiocyte epithelial-to-tomesenchymal transition in murine models of hepatic fibrosis. Hepatology. doi: 10.1002/hep/ 24206.

Dennis G Jr, Sherman BT, Hosack DA, Yang J, Gao W, Lane HC, Lempicki RA. 2003. DAVID: database for annotation, visualization, and integrated discovery. Genome Biol 4: 3. doi: 10.1186/gb-2003-4-9-r60.

Dorrell C, Erker L, Schug J, Kopp JL, Canaday PS, Fox AJ, Smirnova O, Duncan AW, Finegold MJ, Sander M, et al. 2011. Prospective isolation of a bipotential clonogenic liver progenitor cell in adult mice. Genes Dev (this issue). doi: 10.1101/gad.2029411.

Dudas J, Elmaouhoub A, Mansuroglu T, Batusic D, Tron K, Saile B, Papoutsi M, Pieler T, Wilting J, Ramadori G. 2006. Prosperorelated homeobox 1 (Prox1) is a stable hepatocyte marker during liver development, injury and regeneration, and is absent from 'oval cells.' Histochem Cell Biol 126: 549-562.

Fickert P, Stoger U, Fuchsbichler A, Moustafa T, Marschall HU, Weiglein AH, Tsybrovskyy O, Jaeschke H, Zatloukal K, Denk H, et al. 2007. A new xenobiotic-induced mouse model of sclerosing cholangitis and biliary fibrosis. Am I Pathol 171: 525-536. 
Shin et al.

Furuyama K, Kawaguchi Y, Akiyama H, Horiguchi M, Kodama S, Kuhara T, Hosokawa S, Elbahrawy A, Soeda T, Koizumi M et al. 2011. Continuous cell supply from a Sox9-expressing progenitor zone in adult liver, exocrine pancreas and intestine. Nature Genet 43: 34-41.

Hannenhalli S, Kaestner KH. 2009. The evolution of Fox genes and their role in development and disease. Nat Rev Genet 10: 233-240.

Huang DW, Sherman BT, Lempicki RA. 2009. Systematic and integrative analysis of large gene lists using DAVID bioinformatics resources. Nat Protoc 4: 44-57.

Kaestner KH, Bleckmann SC, Monaghan AP, Schlondorff J, Mincheva A, Lichter P, Schutz G. 1996. Clustered arrangement of winged helix genes fkh-6 and MFH-1: possible implications for mesoderm development. Development 122: $1751-1758$.

Kamiya A, Kakinuma S, Yamazaki Y, Nakauchi H. 2009. Enrichment and clonal culture of progenitor cells during mouse postnatal liver development in mice. Gastroenterology 137: 1114-1126.e14. doi: 10.1053/j.gastro.2009.06.001.

Kubota H, Reid LM. 2000. Clonogenic hepatoblasts, common precursors for hepatocytic and biliary lineages, are lacking classical major histocompatibility complex class I antigen. Proc Natl Acad Sci 97: 12132-12137.

Le Lay J, Kaestner KH. 2010. The Fox genes in the liver: from organogenesis to functional integration. Physiol Rev 90: 1-22.

Matthews VB, Yeoh GC. 2005. Liver stem cells. IUBMB Life 57: 549-553.

Okabe M, Tsukahara Y, Tanaka M, Suzuki K, Saito S, Kamiya Y, Tsujimura T, Nakamura K, Miyajima A. 2009. Potential hepatic stem cells reside in $\mathrm{EpCAM}^{+}$cells of normal and injured mouse liver. Development 136: 1951-1960.

Rieck S, White P, Schug J, Fox AJ, Smirnova O, Gao N, Gupta RK, Wang ZV, Scherer PE, Keller MP, et al. 2009. The transcriptional response of the islet to pregnancy in mice. Mol Endocrinol 23: 1702-1712.

Rountree CB, Ding W, He L, Stiles B. 2009. Expansion of CD133expressing liver cancer stem cells in liver-specific phosphatase and tensin homolog deleted on chromosome 10-deleted mice. Stem Cells 27: 290-299.

Sackett SD, Fulmer JT, Friedman JR, Kaestner KH. 2007. Foxl1Cre BAC transgenic mice: a new tool for gene ablation in the gastrointestinal mesenchyme. Genesis 45: 518-522.

Sackett SD, Gao Y, Shin S, Esterson YB, Tsingalia A, Hurtt RS, Brondell K, Kaestner KH, Greenbaum LE. 2009a. Foxll promotes liver repair following cholestatic injury in mice. Lab Invest 89: 1387-1396.

Sackett SD, Li Z, Hurtt R, Gao Y, Wells RG, Brondell K, Kaestner KH, Greenbaum LE. 2009b. Foxll is a marker of bipotential hepatic progenitor cells in mice. Hepatology 49: 920-929.

Saeed AI, Sharov V, White J, Li J, Liang W, Bhagabati N, Braisted J, Klapa M, Currier T, Thiagarajan M, et al. 2003. TM4: a free, open-source system for microarray data management and analysis. Biotechniques 34: 374-378.

Saeed AI, Bhagabati NK, Braisted JC, Liang W, Sharov V, Howe EA, Li J, Thiagarajan M, White JA, Quackenbush J. 2006. TM4 microarray software suite. Methods Enzymol 411: 134193.

Schmelzer E, Wauthier E, Reid LM. 2006. The phenotypes of pluripotent human hepatic progenitors. Stem Cells 24: 18521858.

Schmelzer E, Zhang L, Bruce A, Wauthier E, Ludlow J, Yao HL, Moss N, Melhem A, McClelland R, Turner W, et al. 2007. Human hepatic stem cells from fetal and postnatal donors. I Exp Med 204: 1973-1987.
Schwartz RE, Reyes M, Koodie L, Jiang Y, Blackstad M, Lund T, Lenvik T, Johnson S, Hu WS, Verfaillie CM. 2002. Multipotent adult progenitor cells from bone marrow differentiate into functional hepatocyte-like cells. I Clin Invest 109: 1291-1302.

Seymour PA, Freude KK, Tran MN, Mayes EE, Jensen J, Kist R, Scherer G, Sander M. 2007. SOX9 is required for maintenance of the pancreatic progenitor cell pool. Proc Natl Acad Sci 104: 1865-1870.

Snykers S, De Kock J, Rogiers V, Vanhaecke T. 2009. In vitro differentiation of embryonic and adult stem cells into hepatocytes: state of the art. Stem Cells 27: 577-605.

Srinivas S, Watanabe T, Lin CS, William CM, Tanabe Y, Jessell TM, Costantini F. 2001. Cre reporter strains produced by targeted insertion of EYFP and ECFP into the ROSA26 locus. BMC Dev Biol 1: 4. doi: 10.1186/1471-213X-1-4.

Tanaka M, Okabe M, Suzuki K, Kamiya Y, Tsukahara Y, Saito S, Miyajima A. 2009. Mouse hepatoblasts at distinct developmental stages are characterized by expression of EpCAM and DLK1: drastic change of EpCAM expression during liver development. Mech Dev 126: 665-676.

Tanimizu N, Miyajima A, Mostov KE. 2007. Liver progenitor cells develop cholangiocyte-type epithelial polarity in threedimensional culture. Mol Biol Cell 18: 1472-1479.

Tephly TR, Gibbs AH, De Matteis F. 1979. Studies on the mechanism of experimental porphyria produced by 3,5diethoxycarbonyl-1,4-dihydrocollidine. Role of a porphyrinlike inhibitor of protohaem ferro-lyase. Biochem J 180: 241244.

Xu J, Kochanek KD, Murphy SL, Tejada-Vera B. 2009. Deaths: final data for 2007. Natl Vital Stat Rep 58: 1-51. 


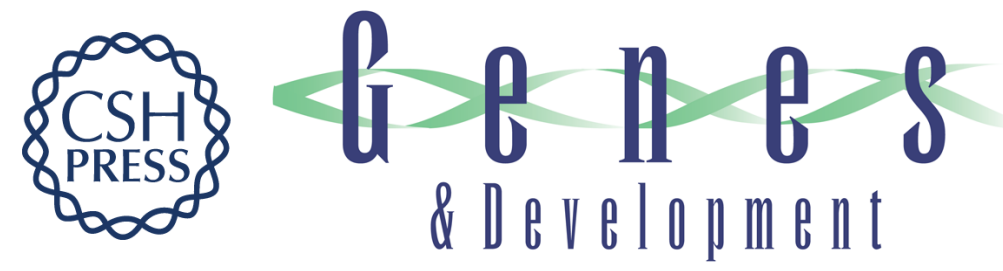

\section{Foxl1-Cre-marked adult hepatic progenitors have clonogenic and bilineage differentiation potential}

Soona Shin, Gabriel Walton, Reina Aoki, et al.

Genes Dev. 2011, 25:

Access the most recent version at doi:10.1101/gad.2027811

Supplemental http://genesdev.cshlp.org/content/suppl/2011/05/31/25.11.1185.DC1
Material

References This article cites 30 articles, 7 of which can be accessed free at:

http://genesdev.cshlp.org/content/25/11/1185.full.html\#ref-list-1

License

Email Alerting Receive free email alerts when new articles cite this article - sign up in the box at the top

Service right corner of the article or click here.

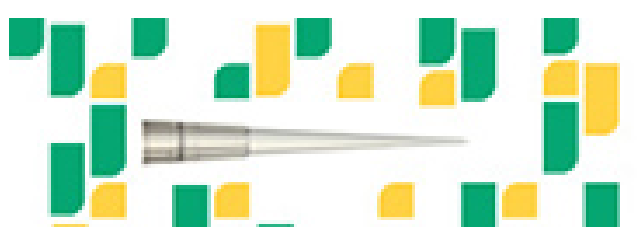

Focused on your science. 